NBER WORKING PAPER SERIES

\title{
LONG-TERM CARE IN LATIN AMERICA AND THE CARIBBEAN? THEORY AND POLICY CONSIDERATIONS
}

\author{
Martín Caruso \\ Sebastian Galiani \\ Pablo Ibarrarán \\ Working Paper 23797 \\ http://www.nber.org/papers/w23797 \\ NATIONAL BUREAU OF ECONOMIC RESEARCH \\ 1050 Massachusetts Avenue \\ Cambridge, MA 02138 \\ September 2017, Revised April 2019
}

The authors thank Ferdinando Regalia, Marco Stampini and three anonymous referees for useful comments and suggestions. The views expressed herein are those of the authors and do not necessarily reflect the views of the National Bureau of Economic Research nor of the InterAmerican Development Bank, its Board of Directors or the countries they represent.

NBER working papers are circulated for discussion and comment purposes. They have not been peer-reviewed or been subject to the review by the NBER Board of Directors that accompanies official NBER publications.

(C) 2017 by Martín Caruso, Sebastian Galiani, and Pablo Ibarrarán. All rights reserved. Short sections of text, not to exceed two paragraphs, may be quoted without explicit permission provided that full credit, including $(\mathcal{C}$ notice, is given to the source. 
Long-Term Care in Latin America and the Caribbean? Theory and Policy Considerations

Martín Caruso, Sebastian Galiani, and Pablo Ibarrarán

NBER Working Paper No. 23797

September 2017, Revised April 2019

JEL No. J14

\begin{abstract}
This paper discusses theoretical and practical issues related to long-term care (LTC) services in Latin America. Demand for these services will rise as the region undergoes a swift demographic transition from its currently young population to a rapidly aging one, especially since the region's aging cohorts are more prone to experience a decline in their functional and physical abilities than elderly people elsewhere in the world. We argue that private insurance markets are ill-equipped to provide coverage to meet the need for LTC, while the amount of personal savings required to afford self-insurance would be prohibitively high. In Latin America LTC may not be an immediate priority, but governments are likely to encourage the development of LTC programs as demand for them steadily grows. In particular, policymakers are probably going to focus initially on LTC programs for the poor and vulnerable, for whom affordability of LTC is a greater problem. We therefore study how basic elements of policy design affect cost-effectiveness of LTC programs by means of a formal model. In a simple context where families can provide care themselves or hire care in a market, we find that pro-poor programs are more cost effective when families have the option to receive cash subsidies, as the opportunity cost of providing care is lower for poor families. Moreover, the availability of in-kind and in-cash choices reduces program costs overall by screening families based on their opportunity cost of providing care.
\end{abstract}

\author{
Martín Caruso \\ Universidad Nacional de La Plata \\ La Plata, \\ Pcia de Buenos Aires \\ Argentina \\ mart.cb007@gmail.com \\ Sebastian Galiani \\ Department of Economics \\ University of Maryland \\ 3105 Tydings Hall \\ College Park, MD 20742 \\ and NBER \\ galiani@econ.umd.edu
}

\author{
Pablo Ibarrarán \\ Inter-American Development Bank \\ 1300 New York Avenue \\ Stop B0700 \\ Washington, DC 20577 \\ and IZA \\ pibarraran@iadb.org
}




\section{Introduction}

Worldwide, the process of population aging has increased the need for long-term care (LTC) services to assist the elderly. According to the US Department of Health and Human Services, "long-term care is a range of services and supports you may need to meet your personal care needs. Most long-term care is not medical care, but rather assistance with the basic personal tasks of everyday life, sometimes called Activities of Daily Living (ADLs)." Most LTC-related activities do not require care providers to have acquired highly specialized skills and customarily family members-typically womenhave provided care for people with disabilities. ${ }^{1}$

This traditional arrangement has come under significant stress as a result of steady demographic and socio-cultural changes. Life expectancy has increased, and with it the probability of needing LTC, while fertility has fallen and female labor force participation has expanded, reducing the pool of family caregivers. In response, developed countries have designed social LTC programs, with an average cost of 1.7 percent of GDP in public expenditure in 11 Organization for Economic Co-operation and Development (OECD) countries (OECD, 2015).

There are two fundamental reasons why LTC will become a more pressing issue in Latin America within the following decades. First, although its population is younger today than the world average, Latin America is aging faster than any other region in the world. Second, there is a body of evidence that shows that its future elderly populations will be prone to dependency situations that require LTC. Life expectancy in Latin America has increased without experiencing the same improvements in living standards and nutrition as the advanced economies (Palloni et al., 2006). As a result, the region's population is more prone to obesity, hypertension, arthritis, and high cholesterol, which increases the probability of early aging and the need for care (AI Snih et al., 2010; Medici, 2011; MatusLópez, 2015).

The literature on long-term care insurance $(\mathrm{LTCl})$ is rather skeptical regarding the competence of private markets to satisfy the needs for LTC. In addition to typical market failures of insurance markets such as adverse selection and moral hazard, $\mathrm{LTCl}$ are vulnerable to several sources of common shocks, especially duration of LTC needs and

\footnotetext{
${ }^{1}$ Throughout this paper, "disability" refers to a situation where a person experiences a long-term decline in their functional and physical abilities that prevents them from performing ADLs autonomously.
} 
future costs. For example, De la Maisonneuve and Oliveira Martins (2013) estimate future costs of LTC in OECD countries and forecast that costs could vary by as much as 5 percent of GDP depending on the scenario. On the demand side, the cost of insurance is rather high for middle and low income families, and it is likely that people would rather allocate additional income to retirement funds, general savings or other sources which, unlike $\mathrm{LTCl}$, are non-contingent. Moreover, the complexity of LTCl contracts makes it difficult to assess value for money (Colombo et al., 2011). In addition, the empirical literature on the effect of incentives on insurance take-up shows that the latter is either hardly responsive (Brown, Coe and Finkelstein, 2007; Bergquist, Costa-Font and Swartz, 2015) or fails to compensate programs costs (Courtemanche and He, 2009; Goda, 2011).

Motivated by the low take-up of LTCl and the intrinsic market failures in this market, a strong case has been made in favor of social insurance programs for LTC (Barr, 2010). Advanced economies have responded to their own aging societies by designing such schemes. Overall, the experience of high income countries provides valuable insights on possible alternatives, although adoption of such programs in Latin America is not straightforward. Fiscal constraints, the limited supply of LTC services by existing public health service providers, and the lack of regulated private LTC markets are of particular concern. But absent any insurance scheme, families in Latin America would have to bear the costs of LTC by themselves. This is something that poor, vulnerable and most middle-income families cannot afford, so the likelihood of some type of policy response will increase as the region's population ages.

These affordability concerns motivated us to develop a formal model to study the costeffectiveness of LTC programs. Albeit simple, our model gives valuable insights. In a context where families respond to the need of LTC by providing care themselves or by purchasing care in a market, we first find that poor families have a preference for in-cash subsidies, making pro-poor programs more effective when they allow for cash transfers. Second, we show that when people differ in their valuation of LTC services, allowing people to choose between in-kind or in-cash subsidies reduces the total cost of the program. Though we study these elements of design in a simple context, we argue that these results are very robust, as they are applications of well-established results in economics.

The remainder of this paper is structured as follows. The next section discusses evidence 
on population aging and the health of aging cohorts in LAC, which drives future demand of LTC. We then discuss the prospects for LTC policy in section 3, with particular emphasis on the rationale for public policy, its motivations and the restrictions behind it. Section 4 features our model on the effect of in-cash and in-kind subsidies, and our corresponding assessment on the cost-effectiveness of the programs. We close the paper with several concluding remarks in section 5 .

\section{Future Need for LTC in Latin America}

The last century or so has issued forth steady demographic changes worldwide. On the one hand, better living standards and improvements in technology and medicine have increased life expectancy. This has been accompanied by complex socio-cultural changes, such as the increase in female labor participation and falling fertility rates. The implication of these phenomena has been a persistent aging of the population. Figure 1 shows the process of population aging for different regions of the world since 1950 (the earliest year with homogenous data worldwide). The process has been steady and generalized worldwide in recent history.

Figure 1. Share of Elderly Population Worldwide

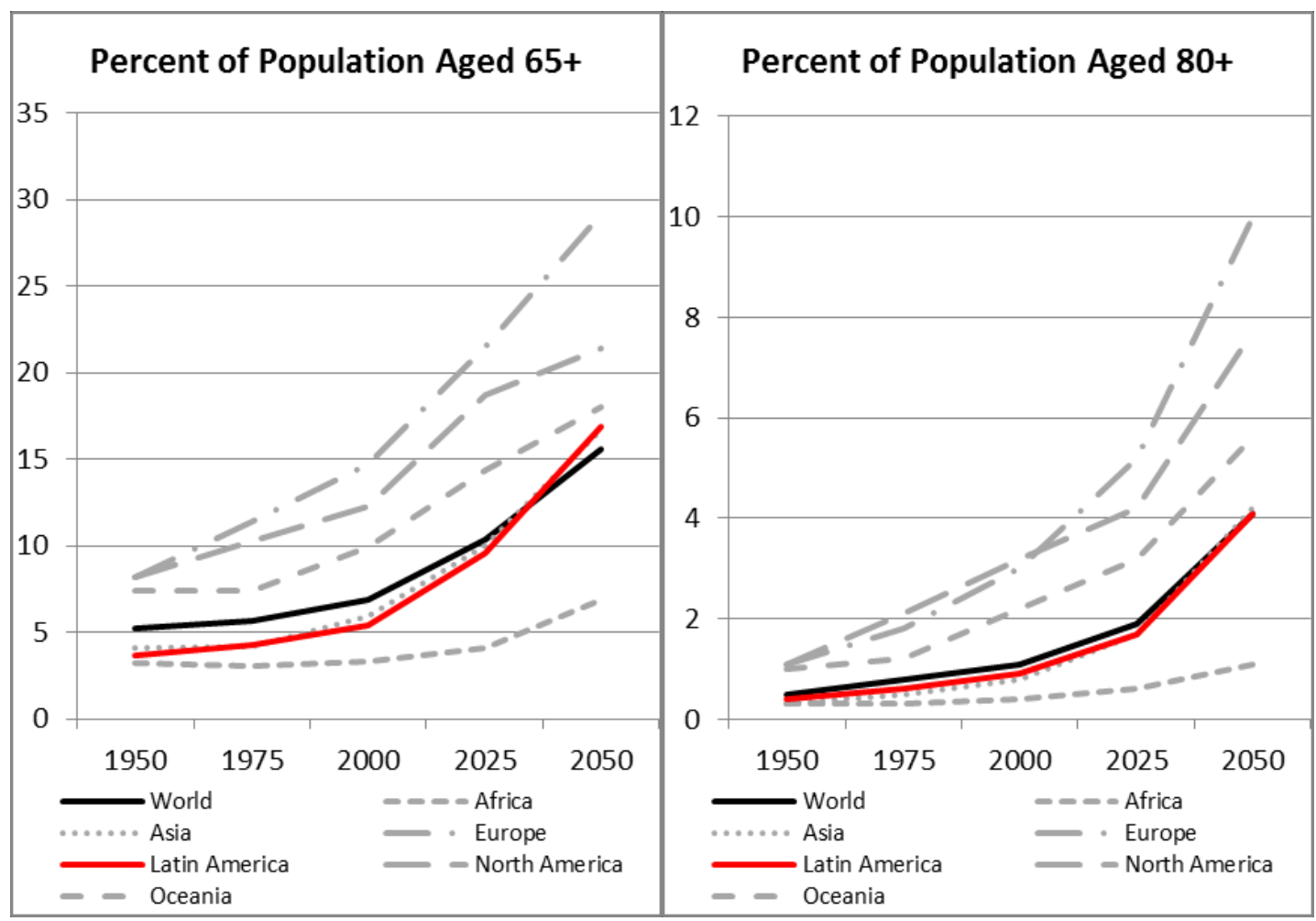

Source: Authors' elaboration based on United Nations (2015). 
We can see that Latin America is still young compared to developed countries, and even slightly younger than the world average; however, its rate of aging is among the highest. According to Kinsella and Phillips (2005), it took France 115 years and Sweden 85 years to change the share of the population over 60 from 7 percent to 14 percent, while Brazil and Colombia will need only 21 and 20 years, respectively.

Figure 2 shows that population aging is occurring in all countries in the region. Nevertheless, there is considerable variation between countries in terms of the overall elderly population rate and the rate of aging.

\section{Figure 2. Share of Elderly Population in Latin America and the Caribbean}

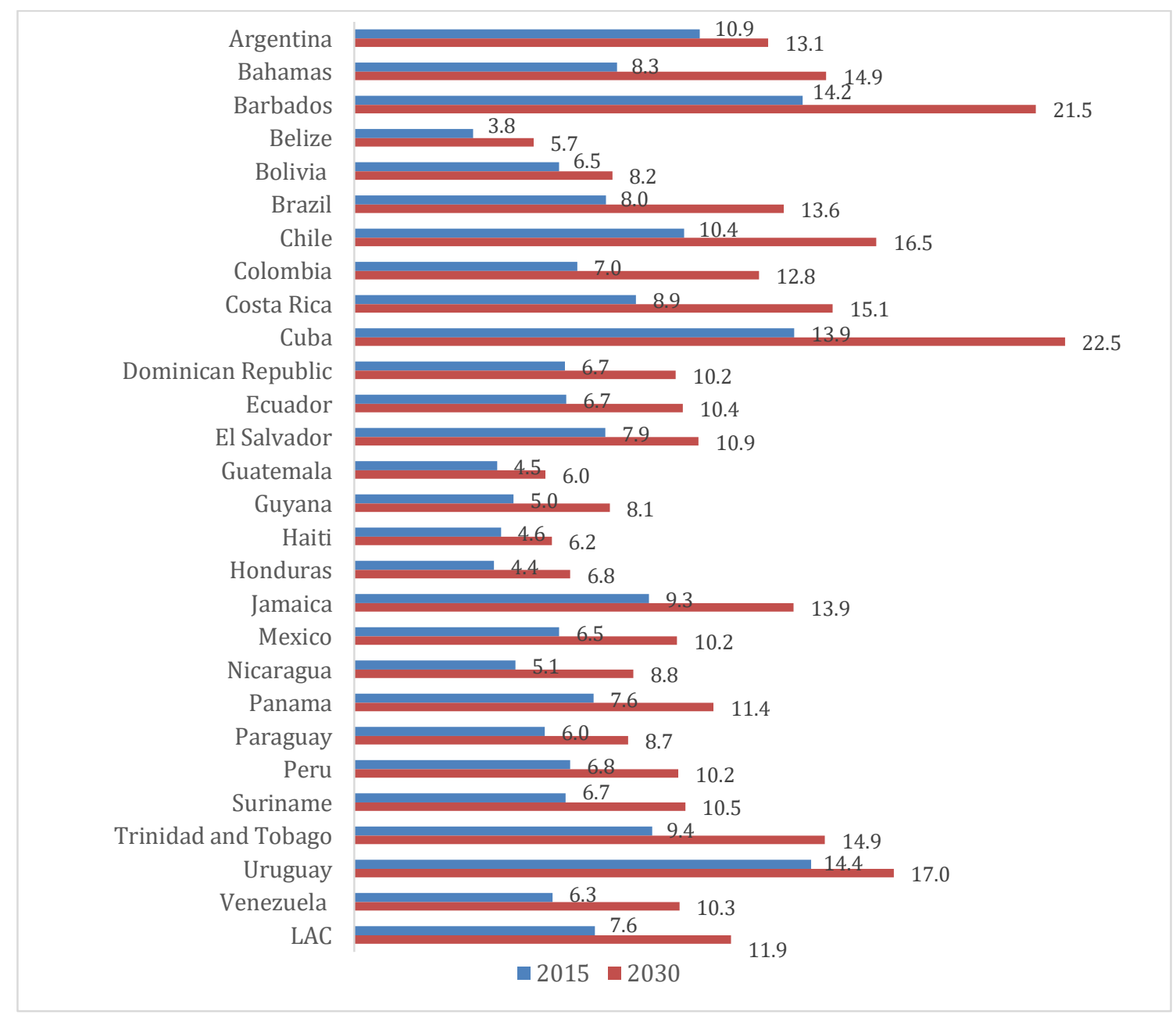

Source: Authors' elaboration based on United Nations (2017).

Although Latin America's population is aging quickly, Figure 1 reveals that aging levels similar to those of the advanced economies in $\mathbf{2 0 0 0}$ will be reached in the region not long before 2050. Figure 2 shows that most countries in the region will have an elderly rate of 
around $15 \%$ or more by 2030 . Overall, in terms of the fertility rate, life expectancy, and share of population over 65, some countries in Latin America are reaching the stage that OECD countries had when they embarked in major reforms to their LTC systems (MatusLópez, 2015).

Although population is aging in Latin America, it is possible, at least in theory, for future demand of LTC to fall in spite of increasing life expectancy. This will happen if the health status with which people reach advanced age improves as well. The literature has developed an interesting hypothesis regarding the health profile of the upcoming generations of elderly in Latin America. Palloni et al. (2006) note that the new elderly will have been a result of large improvements in control and mitigation of the effects of infectious and water-borne diseases. These improvements, however, were not accompanied by substantial increases in standards of living, since poverty and malnutrition were still widespread. As a result, Palloni and Souza (2013) believe that people becoming elderly will be more fragile, with greater prevalence of adult chronic conditions and excess mortality risk. This contrasts with the situation when developed countries reached a similar stage in the demographic transition, where the population aged under better socioeconomic conditions. For example, education levels and average income were higher in OECD countries 20 or 30 years ago than the values today in the Latin American and Caribbean countries that are reaching similar demographic transition thresholds.

There is a considerable body of evidence that documents the link between early-life conditions and adult health. Palloni et al. (2006) find a link between childhood nutritional status and diabetes, and rheumatic fever and heart disease, albeit the former relation is not strong. Similarly, Monteverde, Noronha and Palloni (2009) find that poor early conditions, defined both in terms of child health and socioeconomic status, induce higher rates of disability. McEniry (2013) reviews 20 studies regarding the link between early life conditions and adult health. Her findings indicate that several measures of adverse early life conditions, such as malnutrition, incidence of certain illnesses, and poor socioeconomic status have a strong effect on measures of health at a later age, such as decreased cognition, incidence of heart disease, disability, and mortality rates.

Tables A1, A2 and A3 show the prevalence of several diseases that commonly lead to needing LTC. The tables show that the rate of obesity in Latin America is the highest of any region except for Europe, the prevalence of diabetes is close to world average, and 
old-age dementia is more common in Latin America than in any other region. Though we interpret these diseases as indicators of a high likelihood of needing LTC, again in theory, mortality risk may reduce the length of time in which dependents need LTC and total LTC demand.

To assess whether this is likely, we look at the evolution in life expectancy and healthy life expectancy in the region. Table 1 shows these values at birth for 27 Latin American and Caribbean countries in the years 2000 and 2015. Both life expectancy and healthy life expectancy have increased in all countries in the period under study. Column (7) shows that life expectancy has increased more than healthy life expectancy in all but two countries (Uruguay and Mexico). Table A4 in the Appendix shows the same table for life expectancy and total life expectancy at age 60 , largely leading to the same conclusion.

Table 1. Years of Total Life Expectancy and Healthy Life Expectancy at Birth

\begin{tabular}{|lccccccc|}
\hline & $\mathbf{( 1 )}$ & $\mathbf{( 2 )}$ & $\mathbf{( 3 )}$ & $\mathbf{( 4 )}$ & $\mathbf{( 5 )}$ & $\mathbf{( 6 )}$ & $\mathbf{( 7 )}$ \\
Country & $\mathbf{H L E}$ & $\mathbf{H L E}$ & $\mathbf{( 1 )}$ & $\mathbf{L E}$ & $\mathbf{L E}$ & $\mathbf{( 4 )}$ & $\mathbf{( 6 ) -}$ \\
& $\mathbf{2 0 1 5}$ & $\mathbf{2 0 0 0}$ & $\mathbf{( 2 )}$ & $\mathbf{2 0 1 5}$ & $\mathbf{2 0 0 0}$ & $\mathbf{( 5 )}$ & $\mathbf{( 3 )}$ \\
\hline Antigua and Barbuda & 66.9 & 64.6 & 2.3 & 75.0 & 72.5 & 2.5 & 0.2 \\
Argentina & 68.2 & 65.7 & 2.5 & 76.8 & 74.0 & 2.8 & 0.3 \\
Bahamas & 66.7 & 63.7 & 3.0 & 75.6 & 72.0 & 3.6 & 0.6 \\
Barbados & 66.8 & 65.1 & 1.7 & 75.5 & 73.4 & 2.1 & 0.4 \\
Belize & 62.3 & 61.0 & 1.3 & 70.3 & 68.7 & 1.6 & 0.3 \\
Bolivia & 62.7 & 56.0 & 6.7 & 71.2 & 63.3 & 7.9 & 1.2 \\
Brazil & 65.8 & 61.5 & 4.3 & 74.9 & 69.9 & 5.0 & 0.7 \\
Chile & 69.6 & 67.8 & 1.8 & 79.4 & 77.1 & 2.3 & 0.5 \\
Colombia & 66.8 & 63.4 & 3.4 & 74.9 & 71.1 & 3.8 & 0.4 \\
Costa Rica & 70.7 & 69.0 & 1.7 & 79.4 & 77.4 & 2.0 & 0.3 \\
Cuba & 69.6 & 67.7 & 1.9 & 78.8 & 76.6 & 2.2 & 0.3 \\
Dominican Republic & 64.9 & 61.8 & 3.1 & 73.3 & 69.7 & 3.6 & 0.5 \\
Ecuador & 67.6 & 64.3 & 3.3 & 76.3 & 72.7 & 3.6 & 0.3 \\
Grenada & 64.6 & 62.4 & 2.2 & 73.3 & 70.6 & 2.7 & 0.5 \\
Guatemala & 63.9 & 59.1 & 4.8 & 72.9 & 67.6 & 5.3 & 0.5 \\
Haiti & 55.1 & 50.3 & 4.8 & 63.3 & 58.1 & 5.2 & 0.4 \\
Honduras & 66.6 & 62.8 & 3.8 & 75.0 & 71.1 & 3.9 & 0.1 \\
Jamaica & 66.7 & 64.1 & 2.6 & 75.8 & 72.6 & 3.2 & 0.6 \\
Mexico & 67.4 & 65.6 & 1.8 & 76.2 & 74.5 & 1.7 & -0.1 \\
Panama & 69.3 & 67.4 & 1.9 & 77.9 & 75.8 & 2.1 & 0.2 \\
Paraguay & 65.1 & 62.7 & 2.4 & 74.1 & 71.1 & 3.0 & 0.6 \\
Peru & 67.2 & 63.3 & 3.9 & 75.6 & 71.3 & 4.3 & 0.4 \\
Saint Lucia & 66.3 & 63.6 & 2.7 & 75.4 & 72.2 & 3.2 & 0.5 \\
Saint Vincent and the & 63.6 & 62.3 & 1.3 & 72.3 & 70.9 & 1.4 & 0.1 \\
Grenadines & 63.6 & & & \\
Sao Tome and Principe & 60.5 & 55.3 & 5.2 & 68.5 & 62.9 & 5.6 & 0.4 \\
Trinidad and Tobago & 63.1 & 61.2 & 1.9 & 71.7 & 69.4 & 2.3 & 0.4 \\
Uruguay & 68.7 & 66.6 & 2.1 & 76.8 & 74.8 & 2.0 & -0.1 \\
Venezuela & 65.9 & 64.3 & 1.6 & 73.9 & 72.2 & 1.7 & 0.1 \\
& & & & & & & \\
\hline
\end{tabular}




\begin{tabular}{|llllllll|}
\hline Average & 65.8 & 63.0 & 2.9 & 74.4 & 71.2 & 3.2 & 0.4 \\
\hline
\end{tabular}

Source: World Health Organization (WHO; 2016).

Note: The equivalent lost healthy year fractions required for the healthy life expectancy calculation are estimated as the all-cause rate of years lost because of disability per capita, adjusted for independent comorbidity by age, sex, and country. See WHO (2016) for details.

In comparison, in 2000 life expectancy at birth in Europe was 72.5 years, and healthy life expectancy was 64.2. This is roughly comparable to the same indicators for Latin America and the Caribbean on 2015. In 2015, these figures rose to 77.2 and 68.1 in Europe, implying that the gap between life expectancy and healthy life expectancy increased by 0.5 years. Although this is a simplistic interpretation, if Latin America were to follow the same path as Europe with a 15-year lag, we would expect the gap between life expectancy and healthy life expectancy to keep widening.

All in all, we take this evidence to be indicative of the future rise in LTC demand. The thrust of this rise will be given by population aging. Regarding the health status of future generations of elderly, this may reduce future need for LTC either because conditions have improved enough to reduce LTC, or because health status has worsened to the point in which LTC need is offset by greater mortality risk. Though we do not have the information that would be necessary to assess these issues in detail, aggregate evidence seems to indicate that neither of these channels is strong enough to increase healthy life expectancy more than life expectancy.

\section{Current State of LTC in Latin America and Possibilities for LTC Policies}

\subsection{The State of LTC in Latin America}

Most of the countries in the region have institutions and policies for seniors, and some have advanced in regulations that include aspects related to dependency care. However, comprehensive LTC policies are virtually nonexistent and regulation or direct provision by the public sector is scarce (Gascón and Redondo 2014). Some countries have made progress with specific interventions, in which they have defined quality criteria to achieve the accreditation of institutions providing care services, as well as monitoring and evaluation schemes. One country (Uruguay) has defined a National Integrated Care System that includes LTC, but its interventions prioritize infant care.

Moreover, the region lacks a private $\mathrm{LTCl}$ market. We think that the main reason for this lies in the market failures that are intrinsic to LTCI, as LTCI fails to provide coverage to 
most of the population even in advanced countries. In the US and France, considered the leading markets in terms of coverage (Colombo et al., 2011), insurance covers about 5 percent and 15 percent of the population aged 40 or more, respectively. In Germany, only about 300,000 insurance policies had been sold before the introduction of mandatory insurance in 1995 (Hauschild, 1994). More recently, Arntz et al. (2007) estimate that 9 percent of the German population is covered by private $\mathrm{LTCl}$, while 90 percent is covered by social insurance. Figure 3 shows that the share of private LTCI in total LTC spending is very small, even in the countries with the most widespread coverage.

Figure 3. Share of Private Insurance Spending in Total LTC Spending

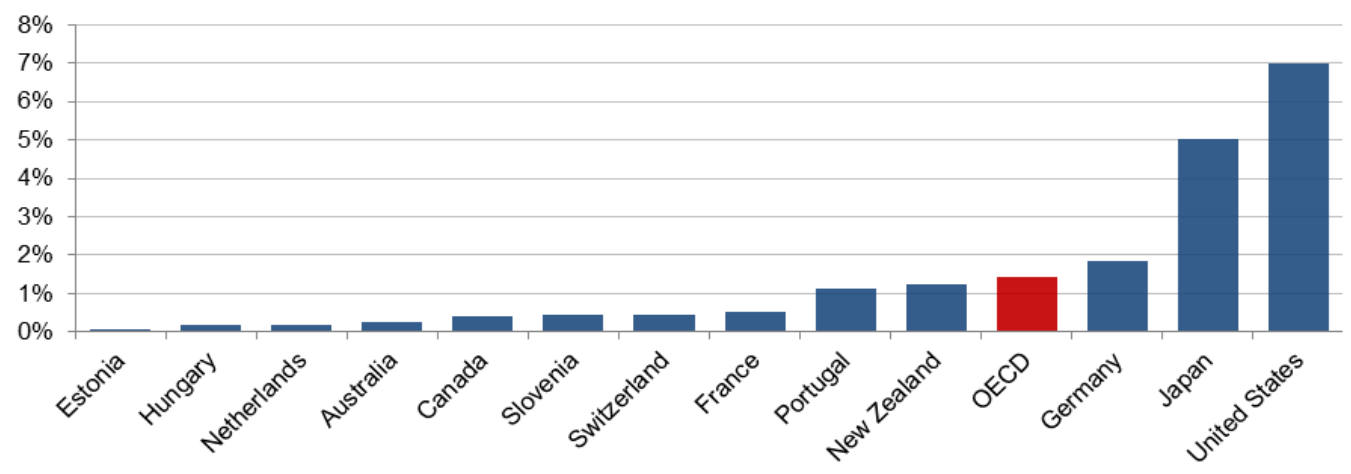

Source: Colombo et al (2011).

Note: Article link is: http://dx.doi.org/10.1787/888932401653.

Absent public LTC programs and private LTCI markets, who provides LTC and how are LTC arrangements made in Latin America and the Caribbean? A report by the International Labour Organization (ILO; 2009) states that only 1 percent of the region's population over 60 lives in nursing homes, and the share that receives formal care at home is also low, so remunerated care is rare and concentrated in families with high incomes. Hence, care is largely provided by family members, demanding substantial time and expense depending on the care requirements of the person in question. Care may also strain the household budget if caregivers need to forgo paid work opportunities to provide care.

In Latin America, the burden of care falls disproportionately -almost exclusively-- on women. Time-use surveys show that the bulk of unpaid housework falls on women 
(Aguirre, 2011), and that women double or triple the amount of time that men dedicate to caring for others (ILO, 2009). Figure 4 confirms that although men spend more time working for wages, women work more overall, since female work in the home more than compensates work for wages. Similarly, González, Raga, and Sibils (2012) establish that survey responses from 544 regional opinion leaders indicate consensus that the responsibility of care falls mainly on women, as shown in Figure 5.

Figure 4. Hours per Week spent in paid and non-paid Work.

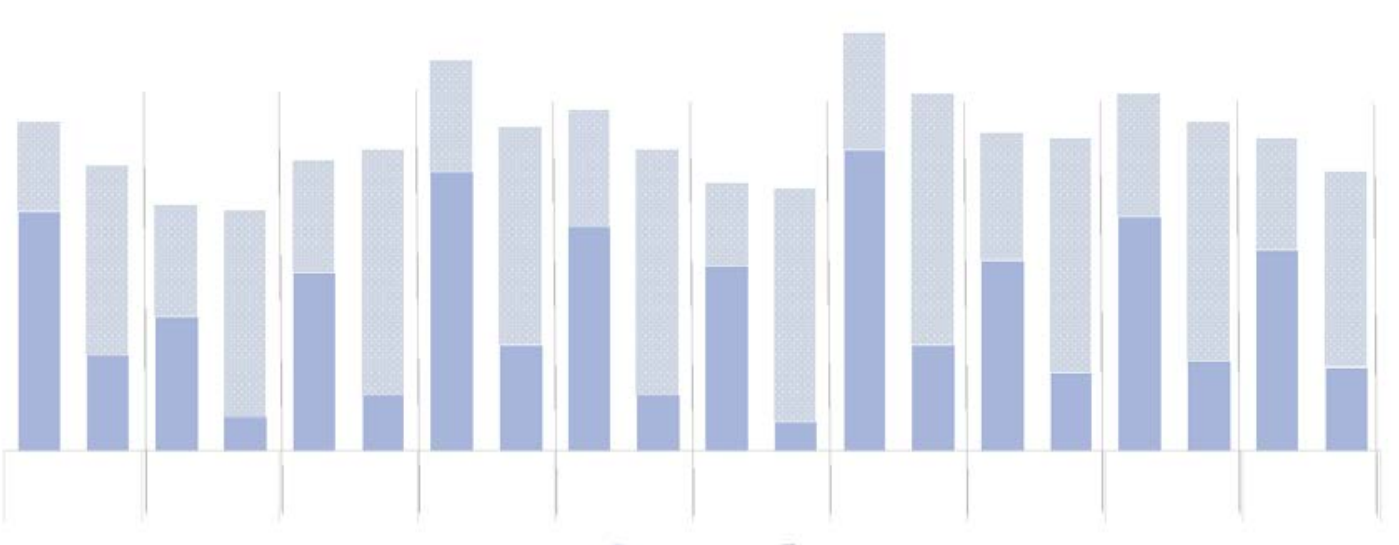

Source: Rico and Robles (2016)

Figure 5. Responses by Gender to the Question: "In Your Opinion, in Your Country of Residence, Who Is Mainly Responsible for the Care of Dependent People, Men or Women?"

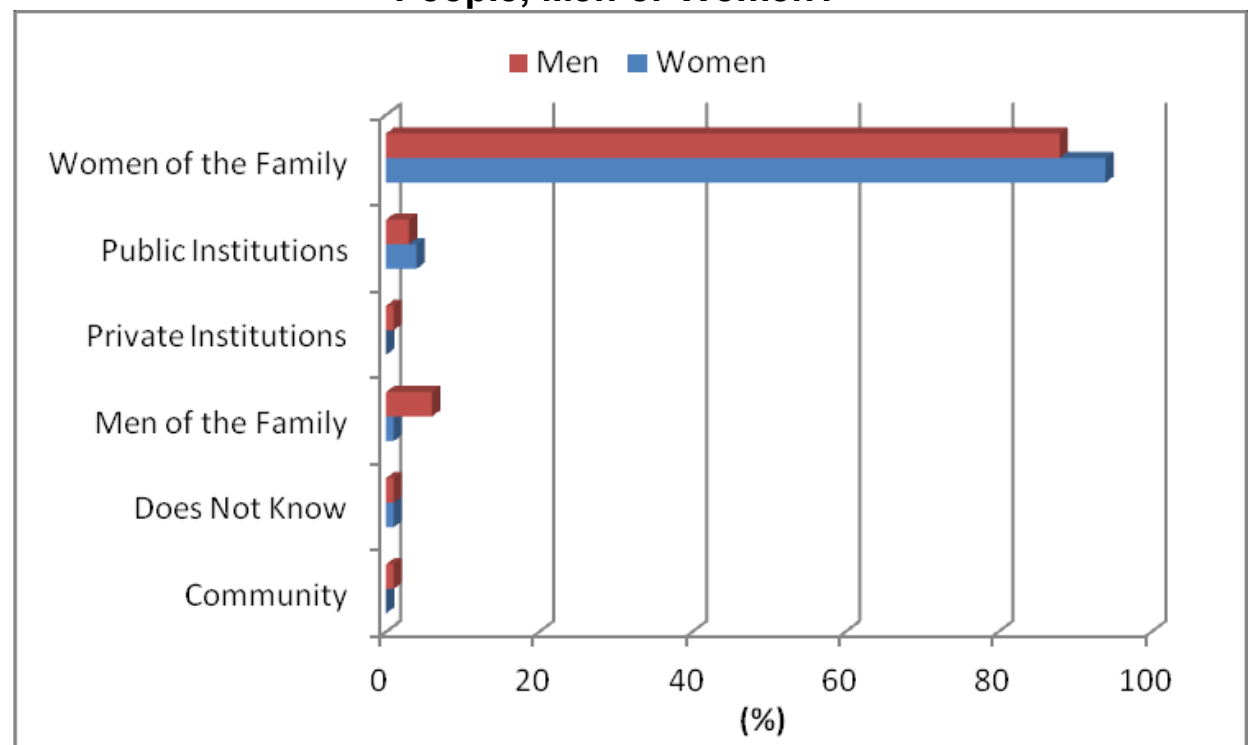

Source: González et al. (2012). 
Note: Based on a survey answered by 544 opinion leaders in Latin America.

Having laid out a diagnostic of the state of LTC in Latin America, we turn to discuss the likelihood of LTC policies being put in place, as well as the most likely objectives for these policies.

\subsection{The Room for LTC Policies}

While the increased demand for LTC in the region has been documented, questions regarding government involvement remain unresolved. Any discussion of public LTC needs to address its financing. Barr (2010) makes the case that actuarial insurance is superior to self-insurance and social insurance programs are superior to private ones, so there are benefits to instituting social insurance. However, comprehensive LTC programs are probably not a priority in Latin America for now. Basic pensions-to ensure that the elderly avoid poverty-are still on the region's to-do list, and so are improvements to the health systems to achieve universal coverage and to enact health policies to deal with the increase in chronic non-communicable diseases. Hence, LTC spending may be seen as a luxury compared with alternative uses of government spending. In addition, the design of LTC programs for workers in the formal sector that contribute to social security, as is done in traditional pension systems, would leave out the region's most socioeconomically disadvantaged groups that work in the informal sector, without access to social security.

On the other hand, as the senior population grows and the need for LTC becomes more prevalent in the region, the demand for and the social return of these programs will rise. How will policy makers react to this increased demand? Figure 6 shows that opinion leaders in the region think that the public sector should be involved in the care of dependent people, and policy makers are likely to respond with greater government involvement. 
Figure 6. Attitude toward the Claim: "The Following Institution Could Be Involved in Care of Dependent People ..."

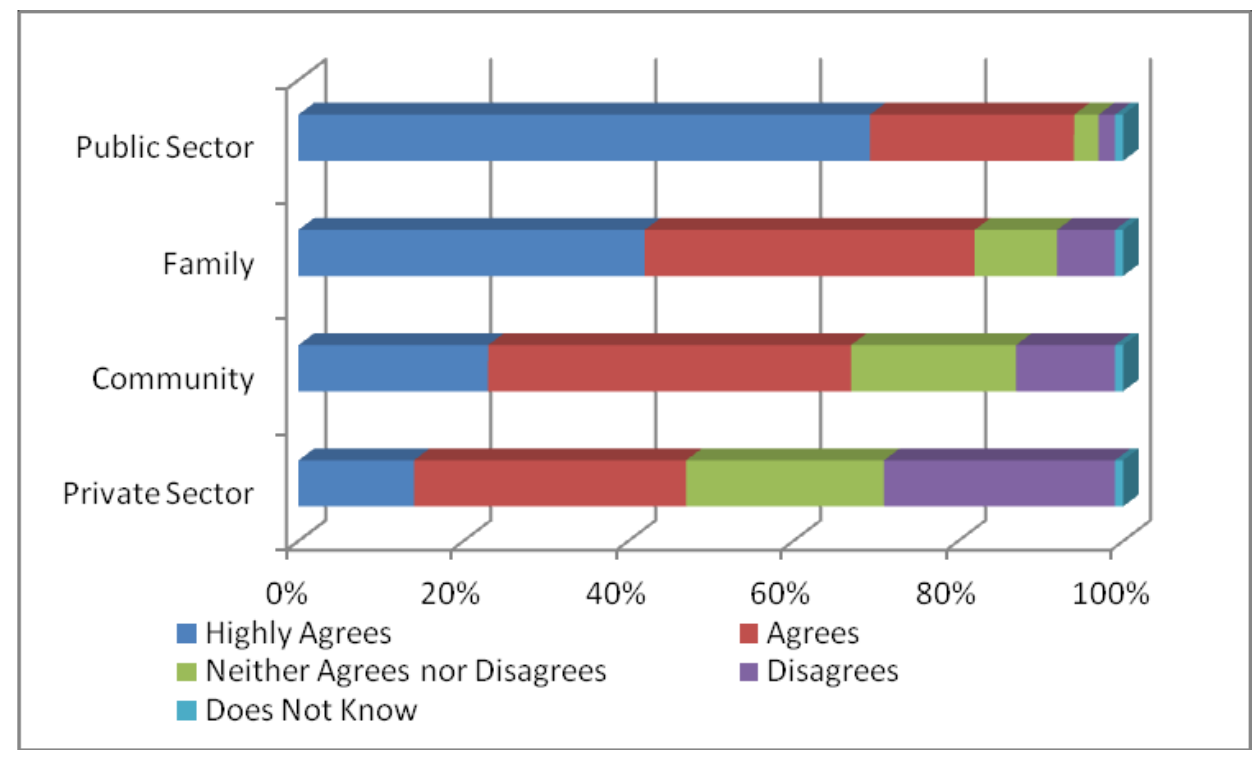

Source: Authors' elaboration based on González et al (2012).

Note: Based on a survey answered by 544 opinion leaders in Latin America.

In addition to the issue of whether the government should launch LTC programs based on an analysis of social costs and benefits, which is a normative statement, a related question is whether and when a government will do so, which demands a positive reasoning. As we said before, an active stance on behalf of the government is to be expected as demand for LTC grows. However, several factors in the policy making process may speed the development of LTC programs. The fact that the region is early in its demographic transition implies that most of the costs of LTC programs would be deferred, and short-term political capitalization of programs is likely. Even if other policies might have higher social returns, the decision making process will possibly lead to some sort of public intervention regarding elderly care in general and LTC in particular. These arguments lead us to believe that there is a large probability that LTC programs will be deployed sooner rather than later.

There are at least three vital aspects of LTC policy that must be dealt with. The first is the setup of a normative framework for the provision LTC services. The first goal of these 
norms is to set standards for LTC provision, like defining the responsibilities of caregivers, the training that is necessary to provide each type of care, and so on. In addition, regulation is also needed to facilitate a market for care, with a special focus on the supply side. We believe these aspects would better be addressed from the perspective of health economics, and so we will not discuss the issue further in this paper.

The second aspect is to define a target population for LTC programs. At first, it seems that LTC policies are necessary for all people who reach a stage of dependency. However, one key aspect that defines at least two distinct segments is affordability. For dependents who can afford LTC, addressing regulatory aspects alone will go to great lengths. On the other hand, policies aimed at relieving the burden for families who cannot afford LTC will demand a more proactive stance from the government. The third element is how to finance LTC, which we discuss separately for each of these segments below.

First, we discuss LTC policies for families who can afford it. The literature on LTC has made the case that actuarial insurance is superior to self-insurance and social insurance programs are superior to private ones, so there are benefits to instituting social insurance (Barr, 2010). As has been shown previously, coverage of LTCI is typically very low, and there are multiple factors that contribute to this. On the demand side, Colombo et al. (2011) note that the complexity of insurance contracts makes it difficult for the insured to assess value for money, and skepticism exists about whether people can actually make informed choices regarding insurance for LTC (Barr, 2010). In addition, there is considerable evidence that the elderly prefer aging in their family homes (Perez et al., 2001; Olsberg, 2005; Wiles et al., 2011; Chomik and MacLennan, 2014), possibly leading to a lower demand for LTCI as a way to avoid being sent to nursing homes by family members (Barr, 2010). Finally, evidence shows that demand is very unresponsive to economic incentives (Courtemance and He, 2009; Goda, 2011; Bergquist, Costa-Font and Swartz, 2015; Brown, Coe and Finkelstein, 2007).

On the supply side, insurers face several problems that put pressure on costs. The first are problems of moral hazard and adverse selection. However, these problems are common to practically all insurance markets, and they are unlikely to preclude the rise of an LTCI market alone. A more important factor is that LTCI providers face at least two sources of common shocks. The first is the possibility that unforeseen changes in life expectancy lead to relatively more or less years of dependency. The second is 
uncertainty regarding the future costs of care. It is generally believed that costs of labor intensive tasks such as LTC will rise because productivity increases in these sectors lag those of the rest of the economy. However, this gap is difficult to predict. De la Maisonneuve and Oliveira Martins (2013) forecast that, in OECD countries, costs could vary by as much as 5 percent of GDP depending on the scenario.

In addition, Latin American countries have a long history of macroeconomic instability, and spikes in defaults of insurance payments should not be discarded. Moreover, compulsory take-up of LTCI will not come without additional problems. Mandatory takeup of workers is unlikely to reach informal workers, who typically account for over one third of the labor force. Under universal pension programs, mandatory LTCI is applicable, but take-up at such a late age will put pressure on premiums and decrease disposable income of the elderly.

By comparison, social insurance schemes share many of the risks of private insurers. Increases in life expectancy or episodes of economics crises may generate a large mismatch between revenues and LTC spending. However, growth and technological progress will boost revenues, and this will probably be enough to cover increases in costs associated to the Baumol disease. All in all, it is not clear that private insurers have a competitive advantage over social insurance schemes. Social insurance programs have to their advantage that these are the norm in advanced countries, and there are valuable insights to be gained from those experiences.

As for families who cannot afford care, we think this is a more natural starting point to start thinking about LTC policies. One reason is that starting at a smaller scale is operationally advantageous before more comprehensive programs are put in place. Moreover, policies in the region have put a great emphasis on relieving poverty, of which the burden associated with LTC is an aggravating circumstance. Thus, LTC policies for the poor would be consistent with the present agenda, and can leverage the institutional infrastructure and acquired know-how of other welfare programs.

As in any targeted program, LTC policies for the poor first require a targeting mechanism to identify who can and cannot afford LTC. Given that the inherent wealth of a person is a largely unobservable factor, policymakers must rely on observable and verifiable characteristics, such as income, age, assets, and labor market status, to determine eligibility. This gives rise to a trade-off between inclusion and exclusion errors-the eligibility of people who should not have received the benefit and the ineligibility of people 
who should have received it.

In Latin America and the Caribbean, high informality largely impedes means testing as a targeting mechanism. However, most countries in the region implement conditional cash transfers to poor households, with eligibility based on proxy means-tests. These are an improvement over alternative targeting mechanisms, but targeting challenges remain. Overall, the fitness of specific characteristics to evaluate affordability varies widely in different countries, and assessment should be done on a case-by-case basis.

Another element of any LTC program is an assessment of the level of dependency of potential beneficiaries, which varies according to the standards defined in each country and sets LTC programs apart from generic income support programs. Well-designed programs therefore require an objective and transparent beneficiary evaluation and the involvement of several actors, such as healthcare systems.

The structure of the public intervention itself is another consideration. The first option is for programs to subsidize the funding of an insurance fund (ex-ante) or to cover expenses as they take place (ex-post). In the first case, governments subsidize take-up of private LTCI. However, as discussed above, it is not clear that LTCI has a competitive advantage over social insurance schemes, and ex-ante insurance would take care of the next generation of the elderly, but not of the elderly in this generation. Moreover, even small copayments of $\mathrm{LTCl}$ are likely to deter low-income families, while it seems more likely that families will contribute to the cost of LTC in case they do need it. For these reasons, granting ex-post subsidies in the event of LTC need is presumably a more adequate element if LTC programs are designed for the poor.

In terms of financing, given the premise that the program is oriented towards poor families, we presume the cost of LTC programs comes from general revenues. However, fiscal stances in Latin America are not in the position of largesse that they were in recently, and we expect LTC policies to have restricted budgets. In said context, it will become necessary for policy makers to adopt schemes that maximize the costeffectiveness of LTC programs.

The last element of subsidies is whether these are in-kind, in-cash or a combination of both. Programs granting cash subsidies seem appropriate to meet the dual goal of providing care and easing the financial burden on poor families. On the other hand, there may be cases in which cash transfers might be insufficient to provide adequate care, for 
example if care is too complex to be provided by family members and unaffordable for them. If this were the case, families would be better off with in-kind subsidies. We believe this a central element in the design of an LTC program for the poor. Accordingly, we dedicate the next section to analyze the effectiveness of cash-for-care and in-kind care programs for the poor. Our study yields clear conclusions regarding their overall welfare effect and overall program costs.

\section{LTC Provision: A Simple Model}

\subsection{The Model}

In this section, we develop a simple model to set the discussion on some features of an LTC system. We build a simple model that focuses on the effects of cash vis-à-vis inkind services, in the context of a targeted LTC program. It is noteworthy that little attention has been put into the effects of LTC program design. One notable exception is Canta, Cremer and Gahvari (2016), who analyze the crowding out of family care as a result of LTC policies in the context of uncertain child altruism.

Our model aims to deliver results on two main aspects. First, we set out to answer what type of subsidy is better suited for the poor and vulnerable, cash transfers or in-kind services. Second, since budget restrictions are an important constraining factor, the model is intended to identify how to boost the cost-effectiveness of this type of program. For the remainder of this section, we will assume that the population of beneficiaries has already been selected, although we will discuss this issue further in the next subsection.

To begin, we assume each family has the following composition: There is one individual who needs an amount $x$ of care. We can think of $x$ as the hours of care needed in a given time interval; the greater $x$ is, the more attention the dependent family member requires. The family purchases $x_{m} \geq 0$ units of care in the market at a price $w_{m}$ and provides $x_{f} \geq 0$ units of care itself. We assume $x_{m}$ and $x_{f}$ are perfect substitutes. We think this is the natural starting point to begin assessing LTC policies, as, historically, formal LTC arrangements have taken the place of informal ones. What is more, this is consistent with an extensive empirical research that finds a substitutability relation between formal and informal care (La Sasso and Johnson, 2002; Van Houtven and Norton, 2004; Bonsang, 2009). Moreover, analyses based on exploiting regional variation in availability of public programs show decreases in formal home care (McKnight, 2006) and increases in informal care (Golberstein, et al. 2009) in response to reductions in Medicare reimbursements. Nevertheless, we will discuss the effect of 
non-substitutability further below.

Utility is defined at the family level and depends on income available for consumption of goods other than LTC, and utility delivered by leisure. Family income is the product between the supply of work $l$ and the market wage $w_{l}$. We assume the market wage is different for each family so that we can study how behavior changes in different income groups. Moreover, we assume the wages belong to the interval $\left[\underline{w_{l}}, \underline{w_{l}}\right]$, with $\underline{w_{l}}<w_{m}<$ $\underline{w_{l}}$. This implies that families can earn wages above or below the cost of care. In practice, we assume the upper bound on wages is not too much higher than $w_{m}$, as the program is targeted towards the poor. To keep matters simple, we assume the utility function has the following Cobb-Douglas form

$$
u=\alpha \ln \ln Y+(1-\alpha) \ln \ln \left(\Omega-\left(l+x_{f}\right)\right)
$$

which is subject to the following budget constraint:

$$
Y=l w_{l}-x_{m} w_{m}
$$

Where $Y$ is income available for consumption and $\Omega$ is the maximum amount of time available, so that $\Omega-\left(l+x_{f}\right)$ is the amount of free time. Let us define this magnitude as $L$ for leisure. We assume LTC needs are not high enough to take up all available time, that is $\Omega>x$. Given the Cobb-Douglas form, this ensures a solution where some time is left for leisure and some for work. Now we can define the family's utility maximization problem (UMP) as

$$
\begin{gathered}
\alpha \ln \ln Y+(1-\alpha) \ln \ln \left(\Omega-\left(l+x_{f}\right)\right) \\
\text { s.t. } Y=l w_{l}-x_{m} w_{m} \quad x \leq x_{m}+x_{f} l+x_{f} \leq \Omega
\end{gathered}
$$

We can rewrite this problem as the following Lagrangian

$$
\alpha \ln \ln \left(l w_{l}-x_{m} w_{m}\right)+(1-\alpha) \ln \ln \left(\Omega-l-x_{f}\right)+\lambda_{x}\left(x_{m}+x_{f}-x\right)+\lambda_{\Omega}\left(\Omega-l-x_{f}\right)
$$

The first-order conditions (FOCs) to this problem are

$$
\frac{\partial L}{\partial l}=\frac{\alpha}{Y} w_{l}-\frac{1-\alpha}{L}-\lambda_{\Omega} \leq 0 ; \quad l \geq 0 ; \quad l\left(\frac{\alpha}{Y} w_{l}-\frac{1-\alpha}{L}-\lambda_{\Omega}\right)=0
$$




$$
\begin{array}{rlrl}
\frac{\partial L}{\partial x_{f}}=-\frac{1-\alpha}{L}+\lambda_{x}-\lambda_{\Omega} & x_{f} \geq 0 ; & & x_{f}\left(-\frac{1-\alpha}{L}+\lambda_{x}-\lambda_{\Omega}\right)=0 \\
\leq 0 ; & & x_{m} \geq 0 ; & \\
\frac{\partial L}{\partial x_{m}}=-\frac{\alpha}{Y} w_{m}+\lambda_{x} \leq 0 ; & & \left.\frac{\alpha}{Y} w_{m}+\lambda_{x}\right)=0 \\
\frac{\partial L}{\partial \lambda_{x}}=x_{m}+x_{f}-x \geq 0 ; & \lambda_{x} \geq 0 ; & \lambda_{x}\left(x_{m}+x_{f}-x\right)=0 \\
\frac{\partial L}{\partial \lambda_{\Omega}}=\Omega-l-x \geq 0 ; & \lambda_{\Omega} \geq 0 ; & & \lambda_{\Omega}\left(\Omega-l-x_{f}\right)=0
\end{array}
$$

As we said before, our assumptions ensure that $l+x_{f} \leq \Omega$ and so we will disregard FOC (5).

The solution to this problem depends on the relevant parameters for the family in question. The following result shows that the decision to hire care or provide it by the family depends crucially on the relation between $w_{l}$ and $w_{m}$.

\section{Lemma 1.}

(i) Assume that the market wage for a family is higher than the cost of buying care at the market: $w_{l}>w_{m}$; then $x_{f}=0$, the family does not provide any care directly and purchases all the necessary care in the market $x_{m}=x$.

(ii) Assume that the market wage for a family is lower than the cost of buying care at the market: $w_{l}<w_{m}$; then $x_{m}=0$, the family does not buy care services and delivers all the necessary care itself $x_{f}=x$.

(iii) Assume that the market wage for a family is equal to the cost of buying care at the market: $w_{l}=w_{m}$; then $x_{m} \geq 0$ and $x_{f} \geq 0$, the family may buy care at the market, provide it directly, or both, with $x_{f}+x_{m}=x$.

Proof of Lemma 1. See Appendix.

Our results indicate that the choice between family-based care and market care depends on the relation between the wage of the family and the cost of buying care at the market. Families whose least productive member may get a wage higher than the cost of hiring care will hire the services from the market, while poorer families will provide care services 
themselves. This is because families with low wage rates have a lower opportunity cost of providing care, and so they would rather provide care themselves. In doing so, it is as if the family could receive a wage rate $w_{m}$ for the first $x$ units of work. On the contrary, families with income above $w_{m}$ would rather hire paid caregivers and work for wages.

That most families choose only one type of care stems from family care being a perfect substitute of market care and the disutility of family caregiving being the same as working for wages. We could add imperfect substitutability between family care and market care, or we could suppose that the productivity of family care is decreasing, for example, because the care needed by the patient becomes more complex or specialized. In these cases, the possibility that the families opt for a mix of market and family care would become more likely. However, the principle that richer families would rely more on market care and poorer families on family care still holds, so there is little to learn in our model from relaxing these assumptions. We will discuss the issue further in the next subsection.

We now include public subsidies, studying first the effect of in-kind subsidies. We assume the family receives $s$ units of care, $s \leq x$. We also implicitly assume that the institution granting the subsidy can observe the value $x$. This assumption is plausible if the value $x$ can be inferred by examining the dependency level of the beneficiary. In a more realistic setting, the agency responsible for the LTC may only observe a noisy indicator of $x$, or the dependent may influence the value of $x$ reported. We will comment on these possible extensions in the following section, and continue assuming $x$ is observable for now. Moreover, we do not assume any particular structure for $s$, although it could be a fixed value for all families or it could depend on $x$ (but not on $x_{m}$ or $x_{f}$ ). We will disregard the restriction $l+x_{f} \leq \Omega$, since we know it is nonbinding. Now the UMP is

$$
\alpha \ln \ln \left(l w_{l}-x_{m} w_{m}\right)+(1-\alpha) \ln \ln L+\lambda_{x}\left(x_{m}+x_{f}-(x-s)\right)
$$

Note that the structure of the problem is essentially unaltered. All we have done is reduce the amount of care the dependent requires. However, the choice of how to provide care has not changed. We state this formally in the following result.

Lemma 2. In the presence of an in-kind subsidy $s \leq x$, such that $x-s \geq 0$ must still be provided, this level of care is provided following the rules (i), (ii) and (iii) of Lemma 1.

Proof. See Appendix.

What, then, is the effect of the subsidy? Poor families must now provide less care 
themselves, and so the marginal cost of working is lower. This implies that they spend more time working for wages, and so they accommodate the extra time available in a mix between increased leisure and disposable income. Rich families must now pay for less care themselves, freeing up part of their income. Since the marginal utility of income is decreasing, their behavior adjusts by decreasing work and enjoying more leisure.

Next, we assume the subsidy is in cash. To keep both types of subsidies comparable, we assume that the subsidy is $S=s w_{m}$, that is, the subsidy equals the cost of the inkind subsidy provided earlier and is thus the same for all families. The UMP is now

$$
\alpha \ln \ln \left(l w_{l}+S-x_{m} w_{m}\right)+(1-\alpha) \ln \ln L+\lambda_{x}\left(x_{m}+x_{f}-x\right)
$$

Again, the structure of the problem has not changed very much, and results (i), (ii) and (iii) will also hold.

Lemma 3. In the presence of a cash subsidy $S$ such that $S \leq x w_{m}$, and assuming the subsidy or the LTC need are not large enough to discourage work altogether in the case $w_{l}<w_{m}$, results (i), (ii) and (iii) hold.

Proof. See Appendix.

In comparison to the previous Lemmas, the results of Lemma 3 are altered somewhat by the possibility that LTC needs are so high that the disutility of providing care is high enough to generate a positive value of $x_{m}$. However, this also implies that $l=0$, and so families rely only on the subsidy to pay for care and for their own consumption. We view these implications as unrealistic, as we find it more reasonable to expect families to work at least a minimum amount. Moreover, this case would require LTC needs to be catastrophic, in the sense that $x$ would be rather close to $\Omega$ (see Mathematical Appendix for greater detail). In what follows, we assume this case in only an extreme example, and that the most likely rules by which care is provided are (i), (ii) and (iii).

If the rules according to which families make decisions have not changed, how does the cash subsidy differ from the in-kind subsidy? One aspect in which the two regimes differ is in their effect on labor supply. We saw that poor families responded to the in-kind subsidy by working more, because care reduced the marginal disutility of labor. In the case of cash subsidies, however, poor families reduce their labor supply. This is because the subsidy increases their income and the marginal utility from working thus falls. Therefore, poor families respond to the in-cash subsidy by working less when compared to the situation without any subsidies. The same happens for rich families: increased 
income reduces the marginal utility of labor and so the labor supply is reduced.

Another interesting dimension is the welfare change induced by both types of subsidy policies. For rich families, the policies differ in the amount of care they hire themselves. With the in-kind subsidy, they would hire $x-s$ units of care, while they hire $x$ units with the cash subsidies. We can prove that this difference of behavior implies no welfare change.

Lemma 4. For families with $w_{l}>w_{m}$, an in-kind subsidy $s$ and an in-cash subsidy $S=$ $s w_{m}$ are equivalent in terms of welfare.

Proof. See Appendix.

We have shown that rich families are indifferent between both types of subsidies. The reason is that care is provided at the market price regardless of the form of the subsidy.

For poor families, however, the type of subsidy does affect the type of care delivered. Under the in-cash subsidy, all the care is provided by the family. Under the in-kind subsidy, on the other hand, only a fraction of the care is provided by the family. We can prove that imposing this restriction makes poor families worse-off with the in-kind subsidy when compared to the in-cash subsidy, as they forego the surplus created by the $w_{m}-$ $w_{l}>0$ differential.

Lemma 5. For families with $w_{l}<w_{m}$, an in-cash subsidy $S$ is preferable to an in-kind subsidy $s=\frac{s}{w_{m}}$.

Proof. See Appendix.

The previous result shows that in-cash subsidies are preferable to in-kind subsidies, for poor families. The reason is that, unlike what happens with rich families, in-kind subsidies do affect the price at which poor families provide care. For poor families, the cost of providing care themselves is lower than market price, hence their utility gain. This should not come as a surprise since, as the previous proof shows, it is only an application of the revealed preference theorem.

Our results show that in-cash subsidies are as good as in-kind subsidies for rich families, and better for poor families. The question is then if there is a rationale for in-kind subsidies at all. We now show that when families have different valuations for the in-kind subsidy, a set of menu contracts in which one provides in-kind subsidies and another provides in-cash subsidies can attain the same welfare effect as an in-kind-only program, 
but at a lower cost. From this point on, we will refer to those families with $w_{l}<w_{m}$ as "low-valuation families" and those families with $w_{l}>w_{m}$ as "high-valuation families."

Note that in our model the different valuation for the in-kind subsidy is given by differences in income level, as families with lower income are more likely to have a market wage smaller than the cash transfer. Nevertheless, when interpreting the results, we will focus on the differences in valuation of the families, and not on the differences in their income levels, since these results apply to any source of heterogeneity in valuation. For example, valuation of in-kind services could be related to the complexity of care required, with families preferring in-kind services for more complex care. We will return to this issue in the discussion in the next subsection.

Lemma 6. Let $U_{i c}(S)$ be the indirect utility function with an in-cash subsidy $S$ and $U_{i k}(s)$ be the indirect utility function with an in-kind subsidy $s=S / w_{m}$. For families with $w_{l}<$ $w_{m}$, there exists a unique $S^{*}<S$ such that $U_{i c}\left(S^{*}\right)=U_{i k}(s)$.

Proof. See Appendix.

This result implies that the low-valuation families are willing to accept a discount in exchange for the subsidy being in cash. High-valuation families, however, would not, because they are indifferent between both types of subsidies if their value in terms of market units of care is the same. The core of this result does not stem from the fact that different families have different income levels. Instead, it arises because families have a different valuation of the in-kind subsidy. Because low-valuation families can provide care at a lower cost, their valuation of the in-kind subsidy is low. Naturally, the opposite is true for families with $w_{l}>w_{m}$.

This result explains why several LTC programs are designed as menu contracts where beneficiaries can choose between an in-kind subsidy and a cash transfer with a discount. One contract, designed for those with the higher valuation for care, would include an inkind subsidy, while the other would offer a cash transfer with a lower value. Since the high-valuation families would use the cash subsidy to purchase care, they would rather choose the more valuable in-kind subsidy. The low-valuation families, however, would choose the cash subsidy, because its value is greater than the cost of providing care themselves. Again, this kind of result has been well studied within economics: it is an application of a discriminating monopoly where valuation for the good is unobservable.

Though useful, we understand that there may be some concern that our results depend 
too strongly on our simplistic assumptions. Moreover, there are several possible ways in which to extend the model. We therefore dedicate the following subsection to discussing the robustness of the results and possible extensions.

\subsection{Robustness, Extensions and Discussion of the Results}

We have built a simple, tractable model to assess the effect of several variables on the decision of how to provide care. It is important to bear in mind that our model was motivated by two conjectures. The first is that LTC programs will be deployed in the region in a reasonably near future. The second is that there are obstacles to universal programs, and so, targeting those who cannot afford LTC seems a more reasonable objective for programs. Although we have discussed the reasonability of these hypotheses, we have otherwise taken them to be true. In what follows, we discuss our results more generally, and whether they are still relevant outside of this setting.

Our model indicates that the type of care provided depends crucially on the income level of the family. This is because relatively poor families have a low opportunity cost of providing care and choose to provide it themselves. For those who are somewhat better off, however, it makes more sense to work for wages and spend this money on hiring care.

A point to be raised against the setup of the model is that families cannot supply care at the market rate $w_{m}$. This is harmful for poor families, which could increase their income if this wage level was available to them. But families do have working opportunities, be it in the care sector or otherwise, and so our model is analogous to one in which there are some costs to provide formal care on the market. These costs may stem from the fact that a market for LTC requires a body of regulations and standards that will inevitably generate some type of costs to suppliers. Though a regulatory framework is necessary for the LTC market, this reasoning shows that excessive regulation is likely to have a regressive effect.

Our results indicate a few main points to explore further, the first being the preference for in-cash subsidies. This comes as no surprise, since an inclination toward lump-sum transfers is well established in economics. In the context of our model, the motivation behind the simultaneous existence of in-cash and in-kind subsidies is nontrivial, since these allow for a screening design that would be impossible with either type of subsidy alone, and contributes to the reduction of the overall cost of the program. We have 
argued that poor families have a strict preference for cash, and this preference implies a willingness to accept it a discount, which naturally translates into cost savings.

In practice, however, policymakers are more likely to opt for in-kind subsidies based on other reasons. For example, the general public may be more receptive toward in-kind than in-cash policies because of paternalistic preferences, the distrust in the use of money by the cash subsidy recipients, or a belief that in-kind care is subject to higher standards and is of better quality than care bought in the market. To address the quality of care issue, many countries offer training and support programs to family caregivers. Additionally, the government, or any other institution in charge of hiring care, could receive sizable discounts by purchasing large amounts of care.

In addition, there is reason to believe that in-kind and in-cash subsidies are different in several political economy aspects. The management of in-kind subsidy probably requires a larger administrative structure, and affects the visibility of officials in charge of LTC programs. Moreover, the greater the involvement of the public sector in LTC, the greater the benefit of political capture and clientelism. Last, as we have explained, regulation is a necessary aspect for the LTC policies, and the possibility that it may be affected by the interests of particular stakeholders is a legitimate concern.

The effect of differences in income levels between families is that these families have different valuations for in-kind services. Those with higher incomes prefer in-kind subsidies because they have a higher valuation for this service, not because they are rich. However, those with low income prefer in-cash subsidies because they have a low valuation of the in-kind subsidies. The result by which menu contracts permit lower program costs is robust to any source of differential valuation. For example, if families valued in-kind services differently because of clinical (e.g., different degrees of disability or complexity of treatment), social (e.g., reluctance to accept care from family members), or economic reasons, the cost-saving result would remain unchanged. This result is analogous to a discriminating monopoly that cannot observe the individual valuation for the good it provides; the design of menu contracts lets families self-select themselves into categories, based on their differences in valuation.

Another result yielded by our model is that families respond differently to in-kind subsidies based on their income level. While in-kind subsidies loosen the budget constraint for better-off families, poor families benefit from a relaxation of their time constraints. Therefore, the former decide to work less as a result of an income effect, 
while the latter decide to work more as a response to the fall in the disutility of working. However, in the case of in-cash subsidies both types of families receive the same income effect and respond by working less.

It should be kept in mind that the results regarding labor supply must be put in the context of this simplified model. The effects on labor supply are actually a secondary feature of the model, and it is not clear if they would prevail in a more realistic characterization of the household structure, the labor market, and the technology for producing household services. For example, if LTC has significant economies of scope with other household activities, in-kind subsidies are unlikely to free up much time to allow for large increases in labor supply. Moreover, changes in labor supply seem less likely under rigid labor market contracts. If there are costs to exit and entry into the labor market, low-income individuals may stay in the labor force even if it is not economical in the short run. Additionally, those for whom access to the labor market is more limited will probably provide care if selection on the decision is possible. These considerations deserve additional empirical research.

Moreover, our model has assumed that family care is a perfect substitute for market care. Although preliminary evidence indicates that formal and informal care are interchangeable, this does not hold for high levels of disability (Bonsang, 2009; Litwin and Attias-Donfut, 2009). Research on South Korea indicates that formal and informal care are substitutes in the intensive margin, but not in the extensive margin (Kim and Lim, 2015). Demand for formal and informal care also responds differently to the use of assistive technologies (AT). ${ }^{2}$ Agree et al. (2005) find that AT substitute informal care but complement formal care. Anderson and Wiener (2013) find that the effect depends on the type of AT. Overall, they find that AT relieve the need for informal care but do not significantly reduce the amount of formal and paid care.

Under imperfect substitution, the choice of in-kind subsidies would be more frequent for low-income people. Additionally, we have paid little attention to family structure. We could assume that an elderly spouse is ill-equipped for certain tasks like assisting the dependent person with movement or bathing. Relaxing the assumption of substitutability

\footnotetext{
${ }^{2}$ According to the United States Assistive Technology Act of 1988 defines assistive technologies as" any product, device, or equipment, modified or customized, that is used to maintain, increase, or improve the functional capabilities of individuals." The World Health Organization has a similar definition (see http://www.who.int/disabilities/technology/en/)
} 
will likely bias the family/market mix in favor of the latter.

In addition, we have assumed that the agency that is responsible for the LTC program can assess the level of dependency $x$ adequately. However, we believe it is likely that agencies will not observe $x$ directly, but will rather observe a noisy version of it, like $x^{\prime}=$ $x+e$. To the extent that the factor $e$ is exogenous and that the agency knows the joint distribution of $x$ and $e, F(x, e)$, the agency can infer the distribution of noise for an observed $x^{\prime}$ level, $F\left(e \mid x^{\prime}\right)$. This will lead the agency to apply a discount a factor that depends on this inferred distribution. On the other hand, if dependents can influence the reported level of $x^{\prime}$ at some cost, that is $e$ is endogenous, and there is some utility to over-reporting (e.g. because caregivers help with household tasks other than LTC), families will over-report dependency to the point that marginal costs match marginal gains from LTC programs.

Assuming families value $e$ less than care, menu contracts like the ones described in the previous section can alleviate the problem of information asymmetry. Under exogenous $e$, an LTC program will generate a screening mechanism, where differences in valuation stem from the share of $e$ in $x^{\prime}$ : the larger $e$ for a given $x^{\prime}$, the lower the value of $x_{s}$ and the larger the discount the family is willing to accept. Under endogenous $e$, and assuming over-reporting generates a cost $c(e)$ with $c^{\prime}>0, c^{\prime \prime}>0$, the setup generates a signaling equilibrium, where some families over-report to show they have a high valuation, while other families do not over-report to avoid the cost $c($.$) , and simply take the discounted$ in-cash subsidy. As was the case in the previous section, the design of menu contracts lowers the overall cost of LTC programs. However, unlike in the previous section, menu contracts limit the allocation of LTC care towards less productive tasks, addressing an inefficiency of a different nature.

Finally, we have assumed the costs of LTC are limited to the cost of providing care, and the wage level for the family is given. In a dynamic setting, we believe that the anticipation of having to provide care in the future may have an effect on human capital acquisition and future earnings. This is more likely if there are rigid labor regulations that make it harder for families to reduce their working hours to make time for LTC. Moreover, if such dynamic incentives exist, it may become necessary to extend LTC programs beyond the poor, and shift towards universal programs to avoid distortions of LTC programs on the inter-temporal wage distribution. 


\section{Concluding Remarks}

Despite the well-known fact that Latin America is aging quickly, policy discussions about the many consequences of this process are limited. In addition, available evidence indicates that the demand for LTC will soar as this process unravels. The reasons are most importantly that demand for LTC naturally grows with an aging population, but also a lack of significant progress in living standards and old-age health status. Ours is among the first studies to present evidence on aging, theoretical and policy discussions from LTC policies in developed countries, their application to the region, and to present a formal model to help guide the debate on the type of LTC policies that are feasible for the region.

The theory and empirical evidence on the matter shows that private markets are illequipped to grant insurance beyond specific population groups. As a result, most advanced countries have come forth with public social insurance programs. In contrast, although most countries have advanced regulations and laws protecting the elderly and encouraging healthy and active aging, and some apply programs to support the elderly, comprehensive LTC policies are nonexistent in Latin America (with the recent exception of Uruguay, which has designed but is yet to implement a LTC system). This means that families must rely on other arrangements to provide care, and the existing evidence shows that families in the region rely very little on remunerated care. The duty falls on family members, with women being the primary source of care.

As the demand for care rises and the issue of LTC becomes more visible, we expect policymakers to come forth with programs designed to guarantee care. One of the reasons has to do with political economy concerns. As is the case with any long-term public expenditure program, the bulk of costs associated with LTC will happen in the future, allowing for short-run political capitalization. Another reason is that LTC programs can follow poverty alleviation program schemes. Typically, poverty alleviation programs acknowledge that the living standards of certain population groups are below acceptable standards, and public programs aim to fill this gap. In this context, need for LTC would be understood as an aggravating circumstance, which requires additional assistance from governments.

In view of this possibility, we study the effect of several subsidy schemes by means of a formal model. Our model yields several interesting insights. The first is the positive association between poverty and a preference for in-cash subsidies. Disadvantaged 
households have lower opportunity costs, and therefore find it more affordable to provide care themselves than hire a caregiver at market rates. This result indicates that in-cash subsidies are likely to be a better match for poverty-alleviation LTC programs. Additionally, in programs where eligible families have varying affordability thresholds, granting the option between in-kind and in-cash programs is likely to reduce the overall cost of the program, as people with lower valuation of in-kind programs are willing to accept in-cash programs at a discount.

We argue that this result is robust to several settings in which families differ in their valuation of in-kind care. Some relevant cases that generate differences in valuation of care are differences in types of care or severity of disability, noisy observation of disability, and endogenous over-reporting of disability level. In all these cases, LTC program administrators can use menu designs to filter families with high and low valuation and reduce program costs.

Moreover, we think that LTC may have an adverse effect on the process of human capital acquisition. This problem is aggravated if workers cannot adjust their working load in the contingency of having to provide LTC for a family member. To the extent that this is true, relieving families of the burden of LTC would have positive dynamic effects. In addition, this setting possibly implies that there are benefits from broadening LTC programs beyond just the poor.

In the end, the issue of LTC will move further into the policy agenda in the medium run. We hope to have contributed by broadening the discussion and presenting our model regarding the welfare effect of LTC programs. 


\section{References}

Agree, E.M., Freedman, V.A., Cornman, J.C., et al. 2005. "Reconsidering Substitution in Long-Term Care: When Does Assistive Technology Take the Place of Personal Care?" Journals of Gerontology Series B: Psychological Sciences and Social Sciences 60(5): S272-S280.

Aguirre, R. 2011. "El Reparto del Cuidado en América Latina." In Duran, M. (Ed.) El Trabajo del Cuidado en América Latina y España. Fundacion Carolina. Madrid, Spain.

Al Snih, S., Graham, J.E., Kuo, Y.F. et al. 2010. "Obesity and Disability: Relation among Older Adults Living in Latin America and the Caribbean. American." Journal of Epidemiology 171(12): 1282-1288.

Anderson, W. L., and J.M. Wiener. 2013. "The Impact of Assistive Technologies on Formal and Informal Home Care." Gerontologist 55(3): 422-433.

Barr, N. 2010. "Long-Term Care: A Suitable Case for Social Insurance." Social Policy and Administration 44(4): 359-374.

Bergquist, S., J. Costa-Font and K. Swartz. 2015. "Long Term Care Partnerships: Are They 'Fit for Purpose'?" CESifo Working Paper Series 5155, CESifo Group Munich.

Bonsang, E. 2009. "Does Informal Care from Children to Their Elderly Parents Substitute for Formal Care in Europe?" Journal of Health Economics 28(1): 143-154.

Brown, J. R., N.B. Coe and A. Finkelstein. 2007. "Medicaid Crowd-Out of Private LongTerm Care Insurance Demand: Evidence from the Health and Retirement Survey." Tax Policy and the Economy 21:1-34.

Canta, C., H. Cremer and F. Gahvari. 2016. "Maybe 'Honor Thy Father and Thy Mother": Uncertain Family Aid and the Design of Social Long Term Care Insurance." Urbana 51(61801).

Colombo, C., L.N. Ana, M. Jerome and T. Frits. 2011. "OECD Health Policy Studies Help Wanted?" Providing and Paying for Long-Term Care. Paris, France: Organisation for Economic Co-operation and Development Publishing.

Courtemanche, C., \& He, D. (2009). Tax incentives and the decision to purchase long- 
term care insurance. Journal of Public Economics, 93(1), 296-310.

De La Maisonneuve, C., and J. Oliveira Martins. 2013. "A Projection Method for Public Health and Long-Term Care Expenditures." Economics Department Working Papers No. 1048. Paris: OECD.

Goda, G.S. 2011. "The Impact of State Tax Subsidies for Private Long-Term Care Insurance on Coverage and Medicaid Expenditures." Journal of Public Economics 95(7): 744-757.

Golberstein, E., D.C. Grabowski, K.M. Langa and M.E. Chernew. 2009. "Effect of Medicare Home Health Care Payment on Informal Care." INQUIRY: The Journal of Health Care Organization, Provision, and Financing 46(1): 58-71.

González, L.E., A. Raga and M. Sibils. 2012. "Consulta de Opinión sobre Políticas de Cuidado en América Latina. Niñas y Niños, Personas Ancianas, Personas con Discapacidad y Personas con Enfermedades Crónicas." Observatorio de lgualdad de Género de América Latina y el Caribe. Santiago, Chile: CEPAL

ILO (International Labour Organization). 2009. Envejecimiento de la Población ¿Quién Se Hace Cargo del Cuidado? Notas OIT: Trabajo y Familia, № 8.

Kim, H. B., \& Lim, W. 2015. Long-term care insurance, informal care, and medical expenditures. Journal of Public Economics, 125, 128-142. Kinsella, K. G., and D.R. Phillips. 2005. Global Aging: The Challenge of Success. Population Bulletin 60(1):3.

La Sasso, A., and R. Johnson. 2002. "Does Informal Care from Adult Children Reduce Nursing Home Admissions for the Elderly?" INQUIRY: The Journal of Health Care Organization, Provision, and Financing 39(3): 279-297.

Litwin, H., and C. Attias-Donfut. 2009. "The Inter-Relationship between Formal and Informal Care: A Study in France and Israel." Ageing and Society 29(01): 71-91.

Matus-López, M. 2015. "Thinking about Long-Term Care Policies for Latin America." Salud Colectiva 11(4): 485-496.

McEniry, M. 2013. "Early-Life Conditions and Older Adult Health In Low- and MiddleIncome Countries: A Review." Journal of Developmental Origins of Health and Disease 4(1): 10-29. 
McKnight, R. 2006. "Home Care Reimbursement, Long-Term Care Utilization, and Health Outcomes." Journal of Public Economics 90(1): 293-323.

Medici, A.C. 2011. "How Age Influences the Demand for Health Care in Latin America" In Cotlear, D. (Ed.) Population Aging: Is Latin America Ready?The World Bank, Washington, D.C.

Monteverde, M., K. Noronha and A. Palloni. 2009. "Effect of Early Conditions on Disability among Elderly in Latin America and the Caribbean." Population Studies 63(1): 21-35.

OECD (Organisation for Economic Co-operation and Development). 2015. "Health at a Glance 2015: OECD Indicators." Paris, France: OECD Publishing.

Palloni, A., and L. Souza. 2013. "The Fragility of the Future and the Tug of the Past: Longevity in Latin America and the Caribbean." Demographic Research 29:543.

Palloni, A., M.R. McEniry, R. Wong and M. Pelaez. 2006. "The Tide to Come Elderly Health in Latin America and the Caribbean." Journal of Aging and Health 18(2): 180-206.

Rico, M. N., and Robles, C. (2016). Políticas de cuidado en América Latina: forjando la igualdad. Serie Asuntos de Género N 140. Santiago, Chile. Comisión Económica para America Latina y el Caribe (CEPAL).

United Nations. 2015. World Population Prospects: The 2015 Revision. New York, New York. United Nations.

Van Houtven, C.H., and E.C. Norton. 2004. "Informal Care and Health Care Use of Older Adults." Journal of Health Economics 23(6): 1159-1180.

WHO (World Health Organization). 2016. "Global Health Observatory." Geneva, Switzerland: WHO. 


\section{Appendix}

Table A1. Obesity rates (aged $18+$ )

\begin{tabular}{|lr|}
\hline Africa & 9.1 \\
Southeast Asia & 4.6 \\
Europe & 25.3 \\
Eastern Mediterranean & 19.5 \\
Latin America and the Caribbean & $\mathbf{2 4 . 1}$ \\
Western Pacific & 6.7 \\
World & 13.2 \\
\hline \multicolumn{2}{|c|}{ Source: World Health Organization } \\
\hline
\end{tabular}

Table A2. Prevalence of diabetes (aged 20-80)

\begin{tabular}{|lr|}
\hline Middle East and Northern Africa & 11.4 \\
East Asia and the Pacific & 8.6 \\
Europe and Central Asia & 6.8 \\
Latin America and the Caribbean & $\mathbf{8 . 7}$ \\
North America & 10.4 \\
Sub-Saharan Africa & 4.8 \\
World & 8.5 \\
\hline \multicolumn{2}{|c|}{ Source: World Development Indicators }
\end{tabular}

Table A3. Standardized prevalence of dementia (aged 60+)

\begin{tabular}{|lc|}
\hline Australasia & 6.91 \\
Asia Pacific, High Income & 5.96 \\
East Asia & 6.61 \\
South Asia & 7.70 \\
Southeast Asia & 7.15 \\
Western Europe & 6.80 \\
Central Europe & 4.65 \\
USA & 5.73 \\
Latin America & 8.34 \\
Sub-Saharan Africa & 4.63 \\
\hline Source: World Alzheimer Report, 2015
\end{tabular}


Table A4. Changes in Healthy Life Expectancy and Life Expectancy at age 60 by Country from 2000 to 2015

\begin{tabular}{|lccccccc|}
\hline & $\mathbf{( 1 )}$ & $\mathbf{( 2 )}$ & $\mathbf{( 3 )}$ & $\mathbf{( 4 )}$ & $\mathbf{( 5 )}$ & $\mathbf{( 6 )}$ & $\mathbf{( 7 )}$ \\
Country & $\mathbf{H L E}$ & $\mathbf{H L E}$ & $\mathbf{( 1 )}-$ & $\mathbf{L E}$ & $\mathbf{L E}$ & $\mathbf{( 4 )}$ & $\mathbf{( 6 ) -}$ \\
& $\mathbf{2 0 1 5}$ & $\mathbf{2 0 0 0}$ & $\mathbf{( 2 )}$ & $\mathbf{2 0 1 5}$ & $\mathbf{2 0 0 0}$ & $\mathbf{( 5 )}$ & $\mathbf{( 3 )}$ \\
\hline Antigua and Barbuda & 15.6 & 14.6 & 1.0 & 19.7 & 18.6 & 1.1 & $\mathbf{0 . 1}$ \\
Argentina & 17.2 & 15.9 & 1.3 & 21.7 & 20.2 & 1.5 & $\mathbf{0 . 2}$ \\
Bahamas & 17.6 & 16.0 & 1.6 & 22.5 & 20.6 & 1.9 & $\mathbf{0 . 3}$ \\
Barbados & 15.5 & 14.6 & 0.9 & 19.7 & 18.7 & 1.0 & $\mathbf{0 . 1}$ \\
Belize & 13.3 & 12.9 & 0.4 & 17.0 & 16.6 & 0.4 & $\mathbf{0 . 0}$ \\
Bolivia & 16.4 & 13.4 & 3.0 & 21.4 & 17.7 & 3.7 & $\mathbf{0 . 7}$ \\
Brazil & 16.5 & 14.2 & 2.3 & 21.5 & 18.7 & 2.8 & $\mathbf{0 . 5}$ \\
Chile & 17.9 & 16.6 & 1.3 & 23.3 & 21.6 & 1.7 & $\mathbf{0 . 4}$ \\
Colombia & 16.9 & 15.2 & 1.7 & 21.7 & 19.6 & 2.1 & $\mathbf{0 . 4}$ \\
Costa Rica & 18.9 & 17.4 & 1.5 & 24.0 & 22.2 & 1.8 & $\mathbf{0 . 3}$ \\
Cuba & 17.6 & 16.7 & 0.9 & 22.5 & 21.5 & 1.0 & $\mathbf{0 . 1}$ \\
Dominican Republic & 17.1 & 16.1 & 1.0 & 21.9 & 20.8 & 1.1 & $\mathbf{0 . 1}$ \\
Ecuador & 17.7 & 16.6 & 1.1 & 22.7 & 21.5 & 1.2 & $\mathbf{0 . 1}$ \\
Grenada & 14.7 & 13.2 & 1.5 & 19.0 & 17.1 & 1.9 & $\mathbf{0 . 4}$ \\
Guatemala & 15.7 & 14.6 & 1.1 & 21.2 & 19.7 & 1.5 & $\mathbf{0 . 4}$ \\
Haiti & 13.1 & 11.6 & 1.5 & 17.6 & 16.0 & 1.6 & $\mathbf{0 . 1}$ \\
Honduras & 17.0 & 15.6 & 1.4 & 22.3 & 20.8 & 1.5 & $\mathbf{0 . 1}$ \\
Jamaica & 17.4 & 16.2 & 1.2 & 22.4 & 21.0 & 1.4 & $\mathbf{0 . 2}$ \\
Mexico & 16.9 & 16.2 & 0.7 & 22.0 & 21.6 & 0.4 & $\mathbf{- 0 . 3}$ \\
Panama & 18.7 & 17.6 & 1.1 & 23.9 & 22.6 & 1.3 & $\mathbf{0 . 2}$ \\
Paraguay & 16.3 & 15.2 & 1.1 & 21.2 & 19.9 & 1.3 & $\mathbf{0 . 2}$ \\
Peru & 16.8 & 15.3 & 1.5 & 21.5 & 19.8 & 1.7 & $\mathbf{0 . 2}$ \\
Saint Lucia & 17.0 & 15.2 & 1.8 & 21.9 & 19.9 & 2.0 & $\mathbf{0 . 2}$ \\
Saint Vincent and the & & & & & & & \\
Grenadines & 14.9 & 14.6 & 0.3 & 19.4 & 19.3 & 0.1 & $\mathbf{- 0 . 2}$ \\
Sao Tome and Principe & 14.1 & 13.3 & 0.8 & 18.3 & 17.6 & 0.7 & $\mathbf{- 0 . 1}$ \\
Trinidad and Tobago & 15.0 & 13.7 & 1.3 & 19.5 & 18.0 & 1.5 & $\mathbf{0 . 2}$ \\
Uruguay & 17.4 & 16.2 & 1.2 & 22.1 & 20.7 & 1.4 & $\mathbf{0 . 2}$ \\
Venezuela & 16.9 & 15.7 & 1.2 & 21.5 & 20.3 & 1.2 & $\mathbf{0 . 0}$ \\
& & & & & & & \\
Average & 16.4 & 15.2 & 1.3 & 21.2 & 19.7 & 1.5 & $\mathbf{0 . 2}$ \\
\hline
\end{tabular}

HALE: healthy life expectancy; LE: life expectancy

Source: World Health Organization (WHO; 2016) 


\section{Mathematical Appendix.}

\section{Lemma 1.}

(i) Assume that the market wage for a family is higher than the cost of buying care at the market: $w_{l}>w_{m}$; then the family does not provide any care directly and purchases all the necessary care in the market, that is $x_{f}=0$ and $x_{m}=x$.

(ii) Assume that the market wage for a family is lower than the cost of buying care at the market: $w_{l}<w_{m}$; then, the family does not buy care services and delivers all the necessary care itself, that is $x_{m}=0$ and $x_{f}=x$.

(iii) Assume that the market wage for a family is equal to the cost of buying care at the market: $w_{l}=w_{m}$; then, the family may choose any combination of family and market care such that $x_{m} \geq 0, x_{f} \geq 0$, and $x_{f}+x_{m}=x$.

Proof of Lemma 1. First, note that the Cobb-Douglas form implies that disposable income and leisure time must be positive, and therefore $l>0$ and $\Omega>l+x$. This implies that the first column of (1) is a strict equality, that the first column of (5) is a strict inequality and $\lambda_{\Omega}=0$. Let us replace these results into equation (1) to generate the following auxiliary expression

$\frac{\alpha}{Y} w_{l}=\frac{1-\alpha}{L}$

To prove (i), assume $x_{m}<x$. Then, because $x_{f}+x_{m} \geq x$, it must be that $x_{f}>0$. Therefore, the first column of FOC (2) is a strict equality. Inserting this expression into the first column of FOC (3) yields

$\frac{1-\alpha}{L} \leq \frac{\alpha}{Y} w_{m}$

And replacing $\left(1^{\prime}\right)$, we get

$\frac{\alpha}{Y} w_{l} \leq \frac{\alpha}{Y} w_{m}$

Which contradicts the assumption that $w_{l}>w_{m}$. Therefore, $x_{m}=x$ and $x_{f}=0$.

To prove (ii), assume $x_{f}<x$ which implies $x_{m}>0$, and that FOC (3) is a strict equality $\frac{\alpha}{Y} w_{m}=\lambda_{x}$. Replacing this value and $\left(1^{\prime}\right)$ on equation (2) generates the following 
expression

$\frac{\alpha}{Y} w_{l} \geq \frac{\alpha}{Y} w_{m}$

Again, this expression contradicts $w_{l}<w_{m}$. Therefore $x_{m}=0$ and $x_{f}=x$.

To prove (iii), because $x>0$, at least one of $x_{f}, x_{m}$ must be positive. Assuming $x_{f}>0$, we have

$\frac{1-\alpha}{L}=\lambda_{x}$

Replacing ( $\left.2^{\prime \prime}\right)$ and $w_{m}=w_{l}$ into (1') yields

$$
\frac{\alpha}{Y} w_{l}-\lambda_{x}=0
$$

Since this expression implies FOC (3) holds, $x_{m}$ may be positive.

The analogous logic holds when assuming $x_{m}>0$.

Lemma 2. In the presence of an in-kind subsidy $s \leq x$, such that $x-s \geq 0$ must still be provided, this level of care is provided following the rules (i), (ii) and (iii) of Lemma 1.

Proof of Lemma 2. Let $x^{\prime}=x-s$. We can write the Lagrangian of the UMP as

$$
\alpha \ln \ln \left(l w_{l}-x_{m} w_{m}\right)+(1-\alpha) \ln \ln \left(\Omega-l-x_{f}\right)+\lambda_{x}\left(x_{m}+x_{f}-x^{\prime}\right)
$$

Which is analogous to the previous problem. Hence, if $w_{l}>w_{m}$ then $x_{m}=x^{\prime}$ and $x_{f}=$ 0 , if $w_{l}<w_{m}$ then $x_{m}=0$ and $x_{f}=x^{\prime}$, and if $w_{l}=w_{m}$ then $x_{f} \geq 0$ and $x_{m} \geq 0$ with $x_{m}+x_{f}=x^{\prime}$.

Lemma 3. In the presence of an in cash subsidy $S$ such that $S \leq x w_{m}$, results (i), (ii) and (iii) hold.

Proof of Lemma 3. Replacing $Y=l w_{l}+S-x_{m} w_{m}$, we can write the Lagrangian of the UMP as

$$
\alpha \ln \ln \left(l w_{l}+S-x_{m} w_{m}\right)+(1-\alpha) \ln \ln \left(\Omega-l-x_{f}\right)+\lambda_{x}\left(x_{m}+x_{f}-x\right)
$$

Note that in this case it does not necessarily hold that $l>0$. We therefore rewrite the FOCs with $Y^{\prime}=l w_{l}+S-x_{m} w_{m}$.

$$
\frac{\partial L}{\partial l}=\frac{\alpha}{Y^{\prime}} w_{l}-\frac{1-\alpha}{L} \leq 0 ; \quad l \geq 0 ; \quad l\left(\frac{\alpha}{Y^{\prime}} w_{l}-\frac{1-\alpha}{L}-\lambda_{\Omega}\right)=0
$$




$$
\begin{aligned}
\frac{\partial L}{\partial x_{f}}=-\frac{1-\alpha}{L}+\lambda_{x} \leq 0 ; & x_{f} \geq 0 ; & x_{f}\left(-\frac{1-\alpha}{L}+\lambda_{x}-\lambda_{\Omega}\right)=0 \\
\frac{\partial L}{\partial x_{m}}=-\frac{\alpha}{Y^{\prime}} w_{m}+\lambda_{x} \leq 0 ; & x_{m} \geq 0 ; & x_{m}\left(-\frac{\alpha}{Y^{\prime}} w_{m}+\lambda_{x}\right)=0 \\
\frac{\partial L}{\partial \lambda_{x}}=x_{m}+x_{f}-x \geq 0 ; & \lambda_{x} \geq 0 ; & \lambda_{x}\left(x_{m}+x_{f}-x\right)=0 \\
\frac{\partial L}{\partial \lambda_{\Omega}}=\Omega-l-x \geq 0 ; & \lambda_{\Omega} \geq 0 ; & \lambda_{\Omega}\left(\Omega-l-x_{f}\right)=0
\end{aligned}
$$

If $x_{f}>0$, FOC (7) implies $\frac{1-\alpha}{L}=\lambda_{x}$. Inserting this into FOC (6) gives $\frac{\alpha}{Y^{\prime}} w_{l}-\lambda_{x} \leq 0$. However, this expression can only hold simultaneously with FOC (8) if $w_{l} \leq w_{m}$.

If $x_{m}>0$, FOC (8) implies $\frac{\alpha}{Y^{\prime}} w_{m}=\lambda_{x}$. We first consider the case in which $l>0$ and FOC (6) is a strict equality $\frac{\alpha}{Y^{\prime}} w_{l}=\frac{1-\alpha}{L}$. Then, FOC (7) can only hold for $w_{l} \geq w_{m}$.

Instead, if $l=0$, since $Y^{\prime}$ must be positive, it must be that $S>w_{m} x_{m}$. Because we imposed $S<x w_{m}$, then $x_{m}<x$ and $x_{f}$ must be positive. FOC's (7) and (8) must therefore be equalities, and FOC (6) can then only hold if $w_{l} \leq w_{m}$. Last, if $x_{m}>0$ and $l=0$, the following condition must hold

$$
x_{m}<\frac{(1-\alpha) S-\alpha(\Omega-x) w_{l}}{\alpha w_{l}+(1-\alpha) w_{m}}
$$

And so, if $S$ is small enough or $x$ is large enough (in the sense that the numerator of the expression on the right-hand-side is negative), then $x_{m}>0$ cannot hold.

Finally, this implies that (i) if $w_{l}>w_{m}$, then $x_{f}=0$ and $x_{m}=x$; (ii) if $w_{l}<w_{m}$, it may be the case that $l>0$ and $x_{f}=x$ and $x_{m}=0$, or $l=0, x_{f}>0$ and $S / w_{m}>x_{m}>0$ with $x_{f}+$ $x_{m}=x$; (iii) if $w_{l}=w_{m}$, it may be the case that $l>0$ and $x_{f} \geq 0$ and $x_{m} \geq 0$, or $x_{f}=x$, $x_{m}=0$ and $l=0$. Hence, if the in cash subsidy is small in the sense that the family does not forgo work altogether, the rules defined by Lemma 1 hold.

Lemma 4. For families with $w_{l}>w_{m}$ an in-kind subsidy $s$ and an in-cash subsidy $S=$ $s w_{m}$ are equivalent in terms of welfare.

Proof of Lemma 4. We start with the UMP when there is an in-cash subsidy. Replacing $S=s w_{m}$ we have

$$
\alpha \ln \ln \left(\operatorname{l~} w_{l}+S-\left(x_{m}-s\right) w_{m}\right)+(1-\alpha) \ln \ln L+\lambda_{x}\left(x_{m}+x_{f}-x\right)
$$

Let $x_{m}^{\prime}=x_{m}-s$ be the amount of care hired above $s$. We can rewrite the problem as 


$$
\alpha \ln \ln \left(l w_{l}+S-x_{m}^{\prime} w_{m}\right)+(1-\alpha) \ln \ln L+\lambda_{x}\left(x_{m}^{\prime}+x_{f}-(x-s)\right)
$$

If we impose the restriction $x_{m}^{\prime} \geq 0$, this problem equals the UMP with an in-kind subsidy. Let $U_{i k}^{*}$ be the solution to the UMP with an in-kind subsidy and $U_{i c}^{*}$ be the solution to the UMP with an in-cash subsidy. Since adding a restriction to the UMP with an in-cash subsidy delivers the UMP with an in-kind subsidy, it must be true that $U_{i c}^{*} \geq U_{i k}^{*}$.

Now, we start with the UMP with an in-kind subsidy. If we define $x_{m}^{\prime \prime} w_{m}=x_{m} w_{m}+S$ as the total cost of care for a family. Since $S=s w_{m}, x_{m}^{\prime \prime}=x_{m}+s$. Replacing these into the UMP with an in-kind subsidy we get

$$
\alpha \ln \ln \left(l w_{l}+S-x_{m}^{\prime \prime} w_{m}\right)+(1-\alpha) \ln \ln L+\lambda_{x}\left(x_{m}^{\prime \prime}-s+x_{f}-(x-s)\right)
$$

Simplifying the restriction, we have

$$
\alpha \ln \ln \left(l w_{l}+S-x_{m}^{\prime \prime} w_{m}\right)+(1-\alpha) \ln \ln L+\lambda_{x}\left(x_{m}^{\prime \prime}+x_{f}-x\right)
$$

If we add the restriction $x_{m}^{\prime \prime} \geq 0$, we have the UMP with an in-cash subsidy. Since we have written the UMP with an in-cash subsidy as the UMP with an in-kind subsidy and a restriction, it must be that $U_{i c}^{*} \leq U_{i k}^{*}$.

Given that $U_{i c}^{*} \geq U_{i k}^{*}$ and $U_{i c}^{*} \leq U_{i k}^{*}$, it must be that $U_{i c}^{*}=U_{i k}^{*}$.

Lemma 5. For families with $w_{l}<w_{m}$, an in-cash subsidy $S$ is preferable to an in-kind subsidy $s=\frac{s}{w_{m}}$.

Proof of Lemma 5. Let $l^{\prime}, x_{f}^{\prime}, x_{m}^{\prime}$ be the solution to the UMP with an in-kind subsidy. Because of Lemma 3, $x_{m}^{\prime}=0$ and $x_{f}^{\prime}=x-s$. We define $U_{i k}^{*}$ as the utility level attained by this combination.

Now, we look at the UMP with an in-cash subsidy, and assume we added the restriction $x_{m} \geq s$. Then, the Lagrangian to the problem would be

$$
\alpha \ln \ln \left(l w_{l}+S-x_{m}^{\prime \prime} w_{m}\right)+(1-\alpha) \ln \ln L+\lambda_{x}\left(x_{m}^{\prime \prime}+x_{f}^{\prime \prime}-x\right)+\lambda_{x_{m}}\left(x_{m}^{\prime \prime}-s\right)
$$

This problem generates the following FOC.

$$
\begin{array}{rlrl}
\frac{\partial L}{\partial l} & =\frac{\alpha}{Y} w_{l}-\frac{1-\alpha}{L} \leq 0 ; & l \geq 0 ; & l\left(\frac{\alpha}{Y^{\prime}} w_{l}-\frac{1-\alpha}{L}-\lambda_{\Omega}\right)=0 \\
\frac{\partial L}{\partial x_{f}}=-\frac{1-\alpha}{L}+\lambda_{x} \leq 0 ; & x_{f} \geq 0 ; & x_{f}\left(-\frac{1-\alpha}{L}+\lambda_{x}-\lambda_{\Omega}\right)=0 \\
\frac{\partial L}{\partial x_{m}}=-\frac{\alpha}{Y} w_{m}+\lambda_{x}+\lambda_{x_{m}} \leq 0 ; & x_{m} \geq 0 ; & x_{m}\left(-\frac{\alpha}{Y^{\prime}} w_{m}+\lambda_{x}\right)=0
\end{array}
$$




$$
\begin{array}{lll}
\frac{\partial L}{\partial \lambda_{x}}=x_{m}+x_{f}-x \geq 0 ; & \lambda_{x} \geq 0 ; & \lambda_{x}\left(x_{m}^{\prime \prime}+x_{f}^{\prime \prime}-x\right)=0 \\
\frac{\partial L}{\partial \lambda_{x_{m}}}=x_{m}^{\prime \prime}-s \geq 0 ; & \lambda_{x_{m}} \geq 0 ; & \lambda_{x_{m}}\left(x_{m}^{\prime \prime}-s\right)=0
\end{array}
$$

Notice that this problem generates the same solution as before, $l^{\prime \prime}=l^{\prime}, x_{m}^{\prime \prime}=s, x_{f}^{\prime \prime}=x_{f}^{\prime}$, delivering the same utility level $U_{i c}^{\prime \prime}=U_{i k}^{*}$.

Now, because $x_{m}^{\prime \prime}>s>0$, FOC (13) is a strict equality. As we explained earlier, the case $l=0$ is an extreme case, and so we focus on $l>0$, implying $\frac{\alpha}{Y} w_{l}=\frac{1-\alpha}{L}$. Replacing this into FOC (12), we get $-\frac{\alpha}{Y} w_{l}+\lambda_{x} \leq 0$. Because $w_{l}<w_{m}$, then $-\frac{\alpha}{Y} w_{m}+\lambda_{x}<0$. Because FOC (13) is an equality, this implies $\lambda_{x_{m}}>0$. Finally, $\lambda_{x_{m}}$ is the shadow cost of restriction $x_{m}^{\prime \prime}-s \geq 0$, and given that it is positive, it implies that utility is greater if the restriction is lifted. Hence, because the maximal utility with an in-kind subsidy can be generated in the UMP with and in-cash subsidy by adding a constraint, and because this constraint is binding, the UMP with an in-cash subsidy must generate a greater utility level.

Lemma 6. Let $U_{i c}(S)$ be the indirect utility function with an in-cash subsidy $S$ and $U_{i k}(s)$ be the indirect utility function with an in-kind subsidy $s=S / w_{m}$. For families with $w_{l}<$ $w_{m}$, there exists a unique $S^{*}<S$ such that $U_{i c}\left(S^{*}\right)=U_{i k}(s)$.

Proof of Lemma 6. We start by showing that $U_{i c}(S)$ is an increasing function of $S$. Note that

$$
U_{i c}(S)=\alpha \ln \ln \left(l^{\prime} w_{l}+S\right)+(1-\alpha) \ln \ln L^{\prime}
$$

Where $l^{\prime}, x_{f}^{\prime}$, and $L^{\prime}=\Omega-l^{\prime}-x_{f}^{\prime}$ are the solutions to the UMP. Our previous discussion implied that for $w_{l}<w_{m}, x_{f}^{\prime}=x$ and $l^{\prime}$ satisfied the first column of FOC (1) with equality. Now, we differentiate $U_{i c}(S)$ with respect to $S$

$$
\frac{d U_{i c}(S)}{d S}=\frac{\alpha w_{l}}{l^{\prime} w_{l}+S} \frac{\partial l^{\prime}}{\partial S} d S+\frac{\alpha}{l^{\prime} w_{l}+S} d S+\frac{(1-\alpha)}{L^{\prime}}\left(\frac{\partial l^{\prime}}{\partial S}+\frac{\partial x_{f}^{\prime}}{\partial S}\right) d S
$$

Since $x_{f}^{\prime}$ is independent of $S, \frac{\partial x_{f}^{\prime}}{\partial S}=0$. Additionally, because of FOC (1), the first and third term add up to zero. Hence

$$
\frac{d U_{i c}(S)}{d S}=\frac{\alpha}{l^{\prime} w_{l}+S} d S>0
$$

Now, note that $U_{i c}(S)>U_{i k}(s)>U_{i c}(0)$. Note that out indirect utility function is continuous. Hence, there must exist some value $S^{*} \in(0, S)$ such that $U_{i c}\left(S^{*}\right)=U_{i k}(s)$. Additionally, since $U_{i c}($.$) is strictly increasing, S^{*}$ is unique. 